\title{
REDUCTTVE DECHLORINATION OF PCDD/F BY ANAEROBIC CULTURES AND SEDIMENTS
}

\author{
Adriaens. $\mathrm{P}^{1}$, and Grbic'-Galic, D. ${ }^{2}$ \\ 1 Department of Civil and Environmental Engineering, University of Michigan, Ann Arbor MI 48109 USA, \\ and 2 Department of Civil Engineering, Stanford University, Stanford CA 94503 USA
}

Key Words: Reductive dechlorination, Methanogens, Anaerobic sediments, Peri-dechlorination

\begin{abstract}
The fate of highly chlorinated (5 to 7 chlorines per molecule) dibenzo-p-dioxin (PCDD) and dibenzofuran (PCDF) congeners was studied in anaerobic microcosms, using polychlorinated biphenyl (PCB)-contaminated Hudson River sediments, and creosote-contaminated aquifer sediments. The PCDD/PCDF concentrations in active microcosms were shown to decrease at higher rates than in chemical and biological controls. The net loss of PCDD/F from active microcosms was up to $35 \%$ higher than in autoclaved controls after extended incubation periods. Lesser chlorinated PCDD/F, identified to be peri-dechlorinated, have been found as the accumulating products resulting from reductive dechlorination under anaerobic methanogenic conditions.
\end{abstract}

\section{INTRODUCTION}

Chlorinated dibenzo-p -dioxins (PCDD) and dibenzofurans (PCDF) have been generated as unwanted byproducts in many industrial and most incineration processes (1-5). Whereas their widespread distribution in the different environmental compartments has been recognized, little is known about their fate in the ultimate environmental sinks, soils and sediments. In particular, the susceptibility of PCDD/F to biological oxidation and reduction reactions has only recently received (limited) attention.

Bioremediation strategies for PCDD/PCDF-contaminated environments would be a highly desirable approach, as it may be considerably less costly than physical-chemical processes, and as it can be used 'in situ ', especially when microbial growth is stimulated via addition of nutrients to the contaminated sites. Little information is available on the potential for microbial transformation of PCDD/PCDF. The highly chlorinated PCDD/PCDF ( 5 to 8 chlorines) will not be susceptible to oxidative transformation, because they already are very oxidized; reductive transformation is more likely to occur with these compounds. Reductive dehalogenation of organohalogen compounds is mainly a cometabolic process whereby a fraction of the electrons generated during oxidation of the microbial growth substrate fortuitously reduce the highly oxidized (i.e. chlorinated) compounds, resulting in a sequential dechlorination reaction (Fig. 1). This mechanism has been shown to be dependent on the concentration and bioavailability of the organohalogen, and can be stimulated by amendment with simple organic growth substrates. 


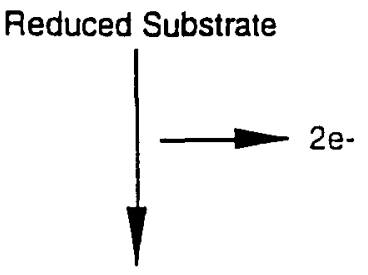

Oxidized Substrate

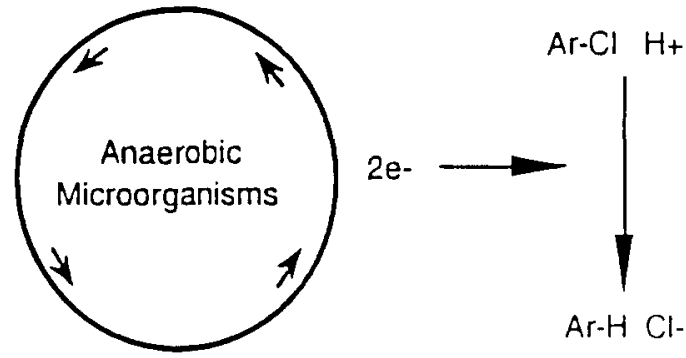

Figure 1: Schematic electron flow diagram representing the general reactions occurring during simultaneous microbial growth and reductive dechlorination of aryl halides (after 10).

Microbially mediated reductive dehalogenation of polychlorinated biphenyls (PCBs) with a high degree of chlorine substitution has been demonstrated to occur in previously contaminated Hudson River sediments (6), and in methanogenic microcosms containing pristine or adapted sediments, spiked with $\mathrm{mg} / \mathrm{kg}$ concentrations of either Aroclor mixtures (7-9) or individual PCB congeners (10). The PCBs presumably serve as a (metabolically nonproductive) alternative 'electron sink' to $\mathrm{CO}_{2}$ for methanogenic populations. Although dechlorination was dependent on the microbial populations studied, generally the meta - and para -chlorines are preferentially removed, while the ortho -chlorines are retained. Structural similarities between PCDD/F and PCBs invoke the potential for similar dehalogenation mechanisms to occur.

Thus, the fate of highly chlorinated PCDD and PCDF congeners (5 to 7 chlorines per molecule) was studied in anaerobic (no other electron acceptor, but carbon dioxide) microcosm incubations using PCBcontaminated Hudson River sediments, dioxin-contaminated aquifer samples (Pensacola. FL), and dichlorophenol-enriched suspended cultures.

\section{METHODS}

The prereduced anaerobic nutrient medium ( $\mathrm{pH} 7.2$ ) used in all incubation studies contained (per $\mathrm{L}$ ): Phosphate buffer $\left(\mathrm{KH}_{2} \mathrm{PO}_{4} / \mathrm{Na}_{2} \mathrm{HPO}_{4}, 40 \mathrm{mM}\right)$; $\mathrm{NaHCO} 3,2.0 \mathrm{~g}$; $\left(\mathrm{NH}_{4}\right)_{2} \mathrm{Cl}, 0.9 \mathrm{~g} ; \mathrm{CaCl}_{2} .6 \mathrm{H}_{2} \mathrm{O}, 0.07 \mathrm{~g}$; $\mathrm{MgSO}_{4} .7 \mathrm{H}_{2} \mathrm{O}$;, $0.13 \mathrm{~g} ; \mathrm{FeCl}_{2} .4 \mathrm{H}_{2} \mathrm{O}, 0.02 \mathrm{~g}$; Cystein- $\mathrm{HCl}+\mathrm{Na}_{2} \mathrm{~S} .9 \mathrm{H}_{2} \mathrm{O}(25+25 \mathrm{~g} / \mathrm{L}$.), $10 \mathrm{ml}$; trace minerals $(500 \mathrm{x}), 0.027 \mathrm{ml}$; vitamin stock $(100 \mathrm{x}), 0.075 \mathrm{ml}$; resazurin $(0.1 \%), 1 \mathrm{ml}$. A mixture of primary substrates was added to augment bacterial growth: acetate $(45 \mathrm{mg} / \mathrm{L}$.), propionate $(30 \mathrm{mg} / \mathrm{L}$.), butyrate $(15 \mathrm{mg} / \mathrm{L}$.), benzoate (10 mg/L.).

Hudson River (HR) sediments containing approximately 100 ppm of 'weathered' endogenous Aroclor 1242 (containing mainly tri-, and tetrachlorobiphenyls), collected downstream of Fort Edward, NY. This sediment is a sandy silt with $7-8 \%$ organic carbon, mostly wood tailings or poorly degradable natural material 
(11). The second inoculum is low organic carbon $(0.02 \%)$ aquifer material (PS) from a creosote-contaminated groundwater aquifer near Pensacola, Florida. The aqueous phase is enriched in organic acids, phenolic compounds, mono- and polyaromatic hydrocarbons, and nitrogen, sulfur and oxygen containing heterocyclic compounds (12).

Microcosms were established in $125 \mathrm{~mL}$ serum bottles containing $50 \mathrm{~mL}$ of the prereduced medium, and inoculated with (dry weight): $(34 \pm 2) \mathrm{g}$ of sediments, and $(80 \pm 4) \mathrm{g}$ of soil. After incubation at $30^{\circ} \mathrm{C}$ for $\mathrm{l}$ month, or until methane-gas production was visible, the microcosms were spiked with PCDD/PCDF. Three replicates were spiked with $100 \mu \mathrm{L}$ of the respective dioxin and dibenzofuran from a $50 \mathrm{mg} / \mathrm{L}$ (except for the mixed HexaCDD congener, $5 \mathrm{mg} / \mathrm{L}$ ) nonane stock solution to give final concentrations of $147 \pm 15 \mathrm{ng} / \mathrm{g}$ and $62 \pm 6$ $\mathrm{ng} / \mathrm{g}$ for sediment and soil, respectively. In addition, duplicate autoclaved biological controls, live biological controls (without PCDD or PCDF), and chemical controls (without inocula) have been established, and were monitored along with active microcosms. The PCDD/PCDF congeners chosen for this study are: $1,2,3,4,7,8$ hexaCDD $1,2,4,6,8,9 / 1,2,4,6,7,9$-hexaCDD, 1,2,3,4,6,7,8-heptaCDD; 1,2,4,6,8-pentaCDF and 1,2,3,4,6,7,8-heptaCDF. During the incubation time, Hudson River sediments and Pensacola soil microcosms were supplied with substrate on a monthly basis.

At regular time intervals $(0,2,4,8,12$, and 14 months, depending on the inoculum), all bottles were manually shaken, decapped, and sampled $(5 \mathrm{ml})$ with a $10-\mathrm{mL}$ glass syringe to contain both aqueous and sediment or soil phase ([0.139 \pm 0.033$] \mathrm{g}$ soil, $[0.082 \pm 0.074] \mathrm{g}$ sediment, all in dry weight), under $\mathrm{N}_{2}$-sparging of the headspace. Octachloronaphtalene $(0.5 \mu \mathrm{g})$ was added as an internal standard, and the sample was twice extracted with two volumes of hexane : acetone (9:1). The solvent was decanted from the soil or sediment, pooled, and 2 $\mathrm{ml}$ of concentrated $\mathrm{H}_{2} \mathrm{SO}_{4}$ were added to precipitate organics. Further sample cleanup was performed as reported earlier (13). The sample was then concentrated to $1 \mathrm{ml}$ in a Rotovap evaporator. To this fraction, $100 \mu \mathrm{L}$ of dodecane-keeper was added. The sample was then further concentrated to $100 \mu \mathrm{L}$ under a gentle stream of $\mathrm{N}_{2}$, and a $2 \mu \mathrm{l}$ aliquot was used for GC/MS and GC-ECD analyses. Recovery efficiencies of PCDD/PCDF were usually in the 55 to $70 \%$ range for inoculated microcosms, and $92 \%$ for the chemical controls (without inoculum).

After 14 months incubation time, selected aquifer- and sediment-inoculated microcosms were decapped, and the supematant (aqueous phase and suspended particles) was decanted from the sedimented phase after centrifugation. Both phases were extracted separately. The supernatant was extracted as outlined earlier, while the sedimented phase was extracted in a Soxhlet apparatus. Accurately weighed wet aquifer material and sediment ([52.2 \pm 6.3$]$ and [34.2 \pm 1.5$] \mathrm{g}$ dry weight, respectively) were placed in a cellulose extraction thimble ( $5 \mu \mathrm{g}$ of octachloronaphthalene added), and extracted for 36 hours in a Soxhlet apparatus containing hexane : acetone (9:1). The extract was quantitatively transferred to a $500 \mathrm{~mL}$ separatory funnel, containing $200 \mathrm{~mL}$ distilled water, $35 \mathrm{~mL}$ acetone, and $25 \mathrm{~mL}$ saturated $\mathrm{NaCl}$ solution. After vigorous shaking for 5 minutes and separation of the phases, the aqueous phase was discarded. The remaining hexane layer $(60 \mathrm{~mL})$ was concentrated to a final volume of $10 \mathrm{~mL}$ in a Rotavap evaporator, and further prepared as outlined earlier. Dodecane $(100 \mu \mathrm{L})$ was added to the clean extract, which was further concentrated to $100 \mu \mathrm{L}$ prior to analyses. All samples were analyzed as described earlier (13). 


\section{RESULTS AND DISCUSSION}

The fate of the spiked PCDD/F (except for 1,2,4,6,8,9/1,2,4,6,7,9- $\mathrm{H}_{\mathrm{X}} \mathrm{CDD}$ ) in anaerobic sediments and soils was investigated. In all cases were the losses over time in the chemical controls negligable compared to the other treatments. However, the disappearance of PCDD/F in the autoclaved controls was in most cases nearly as extensive as that in the active microcosms, indicating the importance of sorption processes during the incubation period. The total decrease of PCDD/F appears to be slightly less in the low organic carbon $(0.02 \%)$ aquifer samples, when compared to the $7-8 \%$ organic carbon Hudson River sediment samples. The initial first-order rate constants for disappearance, calculated from $\log (\mathrm{C} / \mathrm{Co})$ plots, and based on the disappearance rates within the first 6 months, are given in Table 1. The initial removal rates of PCDD/F in active microcosms were 19 to $56 \%$ higher in Hudson River microcosms, and 23 to $56 \%$ higher in ACW aquifer samples, than in autoclaved controls. The net rates of removal in active microcosms were very slow, and calculated to be on the order of $10^{-3}$ to $10^{-4} \mathrm{~d}^{-1}$. These rates correspond well with published rates on PCB desorption from lake sediments (14).

Calculated half lives for the PCDD/F, based on the initial rates of removal, ranged from 1 to 4.1 years (Table 1). The hexaCDDi congener was found to not be degraded, presumably due to the low concentration spiked. The half lives have to be interpreted carefully as rates of removal (i) were not found to follow first order kinetics, (ii) account only for the removal of one or two chlorines per molecule, and (iii) do not account for the residual concentration of congener which does not get dechlorinated.

Table 1: First-Order Disappearance Rates and Calculated Half Lives of Selected PCDD/F in Hudson River (HR) and Aquifer (PS) Microcosm Incubations .

\begin{tabular}{|c|c|c|c|c|c|}
\hline \multirow{2}{*}{$\begin{array}{l}\mathrm{PCDD} / \mathrm{F} \\
\text { Congener }\end{array}$} & \multirow[t]{2}{*}{ Inoculum } & \multicolumn{3}{|c|}{ Pseudo-first-order rates $(n=6-12)$} & \multirow{2}{*}{$\begin{array}{l}\text { Half Lives } \\
\qquad(\mathrm{yr})\end{array}$} \\
\hline & & Active & $\begin{array}{l}\text { Autoclaved } \\
\left(10^{-3} \mathrm{~d}^{-1}\right)\end{array}$ & Net Rates & \\
\hline \multirow[t]{2}{*}{$\mathrm{H}_{7} \mathrm{CDD}$} & HR & $2.32 \pm 0.07$ & $1.85 \pm 0.14$ & $0.46 \pm 0.16$ & 4.1 \\
\hline & PS & $1.31 \pm 0.10$ & $1.01 \pm 0.02$ & $0.30 \pm 0.10$ & 2.9 \\
\hline \multirow[t]{2}{*}{$\mathrm{H}_{6} \mathrm{CDD}$} & HR & $2.86 \pm 0.30$ & $1.92 \pm 0.23$ & $0.94 \pm 0.28$ & 2.0 \\
\hline & PS & $1.46 \pm 0.13$ & $0.80 \pm 0.16$ & $0.66 \pm 0.21$ & 2.9 \\
\hline \multirow[t]{2}{*}{$\mathrm{H}_{6} \mathrm{CDDi}$} & HR & $5.71 \pm 0.16$ & $5.90 \pm 0.14$ & 0 & $\infty$ \\
\hline & PS & ND & ND & ND & ND \\
\hline \multirow[t]{2}{*}{$\mathrm{H}_{7} \mathrm{CDF}$} & HR & $4.13 \pm 0.10$ & $3.22 \pm 0.05$ & $0.90 \pm 0.11$ & 2.1 \\
\hline & PS & $1.34 \pm 0.16$ & $5.86 \pm 0.12$ & $0.75 \pm 0.15$ & 2.5 \\
\hline \multirow[t]{2}{*}{$\mathrm{P}_{5} \mathrm{CDF}$} & $\mathrm{HR}$ & $3.30 \pm 0.04$ & $1.44 \pm 0.02$ & $1.87 \pm 0.05$ & 1.0 \\
\hline & PS & $1.35 \pm 0.18$ & $0.80 \pm 0.13$ & $0.55 \pm 0.22$ & 3.5 \\
\hline
\end{tabular}

ND: Not Determined. 
Therefore, the actual half lives of PCDD/F in the environment may be orders of magnitude higher on account of lower dechlorination rates with fewer chlorines on the PCDD/F molecule, and because residual concentrations may never be biologically available. Incubations with PCDD/F contaminated sediments, and using a range of spiked PCDD/F concentrations may help address this issue of bioavailability.

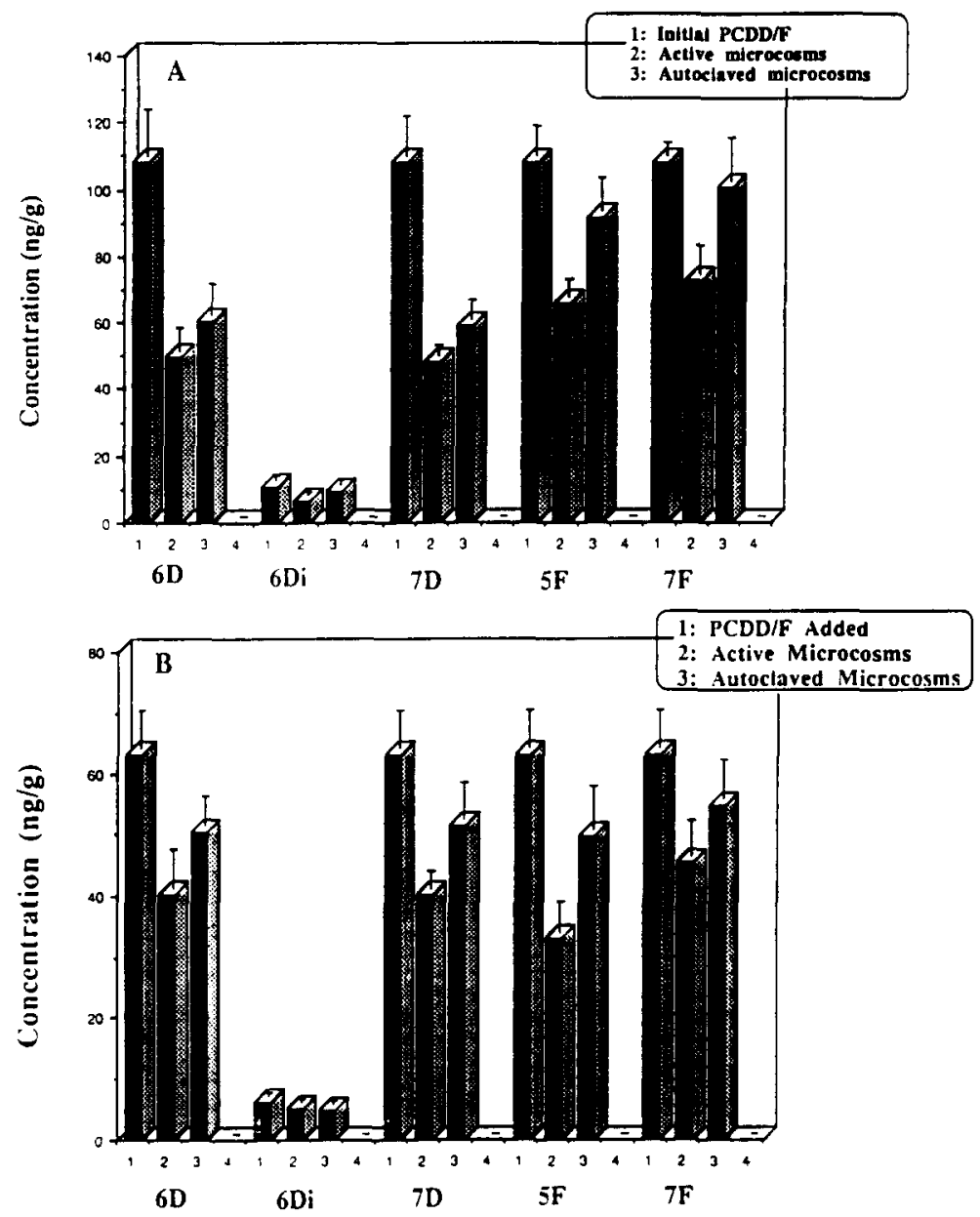

Figure 2: Recovery of PCDD/F in Active and Autoclaved Methanogenic Hudson River (A) and ACW Aquifer Microcosms after Extended Incubation.

The recovery of PCDD/F in both Hudson River and ACW aquifer microcosms is given in Fig. 2. Error bars on the graphs represent triplicate microcosms. Overall recoveries for the PCDD were higher in aquifer microcosms, when compared to Hudson River samples. Though PCDF recoveries in autoclaved microcosms were found to be similar for both inocula, degradation of heptaCDF was more extensive using the Hudson River sediments. Net loss of the spiked PCDD congeners ranged from 11 to $35 \%$, for heptaCDD and hexaCDD respectively. The PCDF congeners were from 25 to $31 \%$ transformed, depending on the inoculum used. 


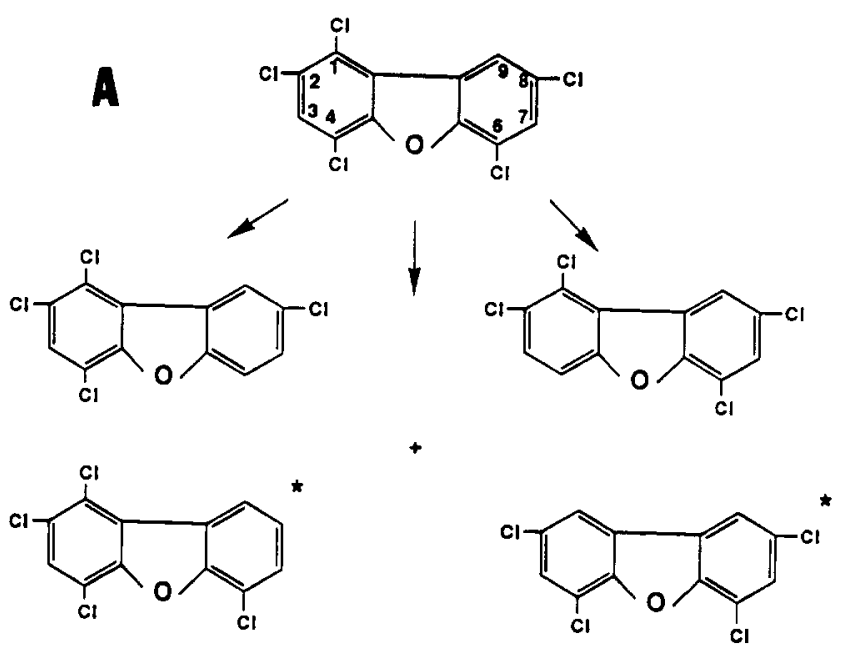

* Noln: Marked congenore cooluto<smiles>Clc1cc2c(cc1Cl)Oc1c(Cl)c(Cl)c(Cl)c(Cl)c1Oc1cc(Cl)c(Cl)c(c1Cl)O2</smiles>

Figure 3. Proposed Dechlorination of 1,2,4,6,8-PentaCDF by Suspended Dichlorophenol-Enriched Cultures (A), and of 1,2,3,4,5,6,7,8-HeptaCDF in ACW Microcosms (B).

Tentative identification of the products indicate that peri-dechlorination was the preferential route of reduction, as has been observed with 1,2,3,4,5,6,7,8-heptaCDD in aquifer microcosms. This observation corroborates our earlier findings of a similar dechlorination pattern found with 1,2,4,6,8-pentaCDF in chlorophenol-enriched sediment cultures, and is contrary to photolytic dechlorination patterns of soil-sorbed PCDD/F. In the latter case, the preferential removal of the lateral chlorines was observed in the case of PCDF, and of peri-chlorines in the case of $\operatorname{PCDD}(16,17)$. Dehalogenated congeners found in Hudson River sediments spiked have not been analyzed on the isomer-specific level. Even though it is too early to evaluate the ubiquity and the extent of the observed microbially-mediated dehalogenation pattern, the selective enrichment of $2,3,7,8$ substituted PCDD/F congeners could be a matter of environmental concern. 


\section{REFERENCES}

1. Olie, K, P. L. Vermeulen and O. Hutzinger. 1977. Chemosphere 8: 455-459.

2. Choudhary, G., Keith, L.H. and Rappe, C. (Eds.) Chlorinated Dioxins and Dibenzofurans in the Total Environment. Butterworth Publishers, Boston, MA. 1983.

3. Erickson, M.D., S.E. Swanson, J.D. Flora, and J.D. Hinshaw. 1989. Environ. Sci. Technol. 23: 462470 .

4. Dickson, L.C., D. Lenoir, and O. Hutzinger. 1992. Environ. Sci. Technol. 26: 1822-1828.

5. Rappe, C., and L.O. Kjeller. 1987. Chemosphere 16: 1775-1780.

6. Brown, J.F., Jr., D.L. Bedard, M.J. Brennan, J.C. Carnahan, H. Feng, and R.E. Wagner. 1987. Science 236: 709-712.

7. Quensen, J.F. III, S.A. Boyd , and J.M. Tiedje. 1990. Appl. Environ. Microbiol. 56: 2360-2369.

8. Quensen III, J.F., S.A. Boyd, and J.M. Tiedje. 1988. Science 242: 752-754.

9. Nies, L., and , T.M. Vogel. 1990. Appl. Environ. Microbiol. 56: 2612-2617.

10. Nies, L. 1993. PhD Dissertation, The University of Michigan.

11. Finkbeiner, H. L., and S. B. Hamilton. 1990. General Electric Company Research and Development Program for the destruction of PCBs, Ninth Progress Report. General Electric Company Corporate Research and Development, Schenectady, N.Y.

12. Godsy, E.M., D.F. Goerlitz, and D. Grbic'-Galic'. 1992. Biodegradation 2: 211-221.

13. Adriaens, P. and D. Grbic'-Galic'. 1992. Proceed. Dechema Conference on Soil Remediation, Karlsruhe, Germany.

14. Coates, J.T. and A. W. Elzerman. 1986. J. Contam. Hydrol. 1: 191-210.

15. Adriaens, P. and D. Grbic'-Galic' 1994. Environ. Sci. Technol. In review.

16. Tysklind, M., Carey, A.E., Rappe, C., and Miller, G.C. 1992. Proceed. Dioxin ' 92 Conference, Vol. 8, pp. 293-296, Tampere, Finland.

17. Miller, G.C., V.R. Hebert, M.J. Mille, R. Mitzel, and R.G. Zepp. 1989. Chemosphere 18: 1265-1274. 